\title{
O CHÃO DA HISTÓRIA: A TERRA E A PRODUÇÃO DE SUJEITOS HISTÓRICOS NA GUERRA DO CONTESTADO
}

\author{
THE GROUND OF HISTORY: THE LAND AND THE CONSTITUTION OF \\ HISTORICAL SUBJECTS IN THE CONTESTADO WAR
}

\author{
DIANA, Marcelo Henrique Nogueira \\ IFC - Instituto Federal Catarinense - Campus Araquari \\ marcelo.diana@ifc-araquari.edu.br \\ MARTINS, Maro Lara \\ UFES - Universidade Federal do Espírito Santo \\ marolara@gmail.com
}

\begin{abstract}
Resumo A relação que pode ser estabelecida entre história e educação ambiental coloca como um dos desafios, nesta articulação, a introdução de novos conceitos historiográficos a serem considerados no campo das práticas pedagógicas. Colocar sob perspectiva histórica as diferentes formas de pensar a natureza e o meio ambiente implica iluminar a polissemia própria dos termos. Neste texto, realizamos um exame do conflito histórico ocorrido no Brasil republicano, a Guerra do Contestado (1912-1916), posicionando a terra como conceito político em disputa naquele conflito. Buscamos explorar as diferentes representações sobre a terra presentes naquele momento entre os sujeitos históricos envolvidos no conflito e chamamos a atenção para a necessidade de tomarmos um conceito relativamente naturalizado, como natureza, a partir também da sua historicidade.
\end{abstract}

Palavras-chave Análise de discurso. Guerra do Contestado. História ambiental.

Abstract The relation between history and environmental education challenges our conventional historiographical concepts to a new use in the field of educational practices. Taking a new historical perspective, we find multiples and different ways to think about the nature and the environment, playing light on the polysemy itself of these concepts. In this article we analyse the historical conflict known as Guerra do Contestado (Contestado War, 1912-1916) that happened in the firsts decades of the new republican regime in Brazil. We attempt to understand the ways that the subjects in War were realising the concept of land as a central issue along that conflict. We seek to explore the different representations about the land on the historical subjects involved with the War. We regard special attention to the importance of considering an apparent unhistorical concept, as nature, also under a point of view full of historicity.

Key words Contestado War. Discourse analysis. Environmental history. 


\section{A TERRA E O CONTESTADO: FORMAS DE SUBJETIVAR}

Embora elemento central no contexto que deu início à Guerra do Contestado (1912-1916), a terra ainda demanda ser tematizada historicamente pela bibliografia especializada naquele conflito. Este será o nosso objetivo neste artigo. Tentaremos apresentar o modo como os diversos grupos sociais em luta na Guerra do Contestado se subjetivaram em relação à terra, isto é, em como eles se tornaram sujeitos históricos significativos e singulares no momento em que se colocaram discursivamente em relação à terra. Se é pelo discurso que podemos conceber os processos de formação dos sujeitos históricos em um determinado evento ou contexto, também será por meio dos sentidos presentes nesses discursos que as diferenças entre os sujeitos históricos podem se fazer representar. Ou seja, as singularidades dos sujeitos estão relacionadas não à individualidade de cada um dos nomes ou personagens citados no conflito, mas através da relação que, entre eles, vem a se estabelecer a diferença subjetiva.

Em trabalho recente sobre a representação dos sujeitos pela historiografia e pela literatura especializada na Guerra do Contestado, a historiadora Katiuscia Maria Lazarin chamou a atenção para o problema dos discursos na história. Segundo a autora, "quando se faz referência ao discurso, ou seja, ao conjunto de enunciados que pertencem a uma mesma formação discursiva, tem-se em mente o que Foucault denomina de prática discursiva", isto é, "como "um conjunto de regras anônimas, históricas, sempre determinadas no tempo e no espaço, que definiram em uma dada época e para uma determinada área social, econômica, geográfica ou linguística, as condições de exercício da função enunciativa"” (LAZARIN, 2004, p. 152). Seguimos, em parte, esta orientação para pensar os discursos sobre a terra em nossa análise.

Sobre o conceito de terra, compreendemos que uma história das formações conceituais operantes sobre um evento ou contexto, em geral, faz assinalar que diferentes modos de conceber ou mesmo de pensar e se implicar com aquele evento ou contexto são plausíveis. O conceito, nessa perspectiva, reconhece a polissemia do seu entendimento, não a unidade de sentidos (KOSELLECK, 2006). Sob este argumento, seguindo a orientação de Koselleck acerca do interesse em uma história dos conceitos, "[a]inda que não se possa depreender, imediata e diretamente, a realidade a partir do conceito, a história dos conceitos tem como premissa refletir 
essa co-incidência" entre formas de entendimento e realidades históricas (KOSELLECK, 2006, p. 114). O autor entende este movimento de interpretação histórica sobre os conceitos como decorrente justamente da "ambiguidade semântica" de determinadas expressões de caráter político e social, que causam "não pouca dificuldade de compreensão". Esta dificuldade histórica-conceitual, para o autor, demonstraria a politização dos conceitos na história, compreendidos então a partir do "campo de experiências" e do "horizonte de expectativas" que a aparição do conceito se faz ver no tempo (KOSELLECK, 2006, p. 98-114).

Em suma, a história dos conceitos recolhe dos registros discursivos a polissemia conceitual e a multiplicidade de valores que informam os discursos na história. O nosso interesse aqui reside sobre essa polissemia conceitual em torno dos discursos sobre a terra produzidos no contexto da Guerra do Contestado. Os discursos sobre a terra são compreendidos como formados por unidades de enunciados que são, por sua vez, "fatos de discurso que merecem ser analisados ao lado dos outros [discursos], que com eles mantêm, certamente, relações complexas, mas não constituem seus caracteres intrínsecos, autóctones e universalmente reconhecidos" (FOUCAULT, 2007, p. 25).

Em certa medida, trata-se de perceber que a terra, neste caso, está colocada muito além do seu conteúdo material ou do simples lugar de fato ou pretexto histórico para a eclosão daquele conflito. Ela é percebida como conceito estruturante dos discursos de identidade e de estranhamento entre os diversos grupos implicados na Guerra. Como conceito fundamental enunciado durante o conflito, a terra estrutura e organiza os diversos sujeitos e os seus interesses entre si, separando-os também em relação aos seus valores sobre o uso ou propriamente o sentido de valor da terra. Podemos dizer que a terra aqui opera como uma representação social, marcada por historicidade e construída de maneira diferente por cada um dos sujeitos históricos singulares. Por isso, percebemos o sujeito histórico a partir de "práticas [que] se constituem em sua narratividade, assim como o sujeito se elabora no interior dos enunciados com os quais opera e nos usos que deles faz" (BOCCHETTI, 2015, p. 49).

Orientado pelas recentes contribuições da história ambiental, o artigo propõe então uma visão pós-construtivista sobre o conceito de natureza e, especificamente, de terra. Nesta visão pós-construtivista, a narrativa histórica pretende não apenas 
contextualizar as práticas ambientais a um determinado período ou problema histórico, mas vai além, ao também colocar em perspectiva a própria noção de natureza. Representada por autores como Bruno Latour e Donna Haraway, esta última perspectiva compreende a natureza enquanto também uma alteridade inserida na cultura (ASDAL, 2003). Desse modo, evita-se reproduzir os esquemas binários que tendem a simplificar as relações entre cultura e natureza em conceitos estanques, já que tanto um quanto o outro conceito somente podem se tornar fatos de discurso quando colocados em mútuo entendimento. No nosso caso histórico particular trata-se, em primeiro lugar, de perceber que por trás dos conflitos sobre a terra na Guerra do Contestado existem procedimentos distintos de interpretação sobre o que vem a ser a terra para cada um dos sujeitos sociais envolvidos naquele contexto.

Os sentidos sobre essa palavra - terra - precisam ser apreendidos em relação aos discursos que os produzem e não através de um a priori que entenderia a terra como sendo algo fora da história. Por isso, ao longo da análise do material histórico e historiográfico referente ao conflito, foi possível organizar as unidades discursivas em torno de quatro sujeitos históricos singulares da Guerra: os coronéis, os militares, os empresários estrangeiros e os caboclos. Evidentemente que outros sujeitos históricos poderiam vir à tona como, por exemplo, a imprensa regional, a fala de representantes políticos e mesmo dos intelectuais, entretanto, devido aos limites da pesquisa com que estamos lidando na análise da Guerra do Contestado, decidimos priorizar o protagonismo daqueles quatro sujeitos históricos diretamente implicados com o conceito de terra.

O conflito que ficou conhecido como a Guerra do Contestado ocorreu, em linhas gerais, na região que se denomina hoje como planalto catarinense, formado pelo Planalto Norte de Santa Catarina, pelo Vale do Rio do Peixe e pela região que se interioriza pelo Meio Oeste Catarinense. Região de conflitos de territórios desde, pelo menos, meados do século $\mathrm{XIX}^{1}$, essa grande formação geográfica e histórica

\footnotetext{
${ }^{1}$ De acordo com Elison Antonio Paim, a "região oeste de Santa Catarina foi, de fato, uma área de muitas disputas. Inicialmente, entre Portugal e Espanha; num segundo momento, entre Brasil e Argentina e, num terceiro momento, entre Paraná e Santa Catarina, originando, inclusive, a Guerra do Contestado (1912-1916), quando só então se definiu que o território pertencia ao estado de Santa Catarina. Para manter o território conquistado do Paraná era preciso 'povoá-lo', para tanto, investiuse num intenso processo de colonização. Mas não bastou definir que as terras pertenciam a Santa Catarina para que elas, realmente, fossem assumidas como tal [...]" (PAIM, 2006, p. 125). Para Paim,
} 
estava sendo disputada pelos Estados do Paraná e de Santa Catarina há alguns anos antes da eclosão do conflito do Contestado em 1912. Região planaltina que, não obstante a sua floresta araucária de mata densa, era vista como inóspita durante todo o período colonial e, em parte, também durante o Império do Brasil.

No início do século $X X$ houve um rápido crescimento da população do planalto catarinense, tornando a região em objeto de atenção por parte dos governos regionais e nacional. De acordo com Paulo Pinheiro Machado (2001, p. 100-101), "o aumento das ocupações e conflitos de terra, o crescimento da exploração da erva-mate e a intensificação dos conflitos de limites com a Paraná, tornaram os municípios planaltinos politicamente mais importantes dentro do contexto catarinense". Na caracterização que Paulo Machado faz, a grande propriedade predominava no planalto meridional, sobretudo, em Curitibanos. Em contrapartida, excetuando-se algumas faixas de terra aproveitadas como pastagens nativas pelos grandes proprietários, nos vales florestais do Taquaruçu, Marombas, Timbó, Paciência e Canoinhas, situados na região de Perdizes, Correntes e nos faxinais e matas do planalto médio e norte, habitava "uma expressiva camada social de posseiros, pequenos sitiantes e ervateiros que irão compor o principal grupo social envolvido na rebelião do Contestado" (MACHADO, 2001, p. 101).

Denominados, em geral, como os caboclos do sertão², termo de sentido mais cultural do que racial ou étnico, para designar a população sitiante do Oeste que vivia do que plantava e caçava, sendo incomum entre eles a prática do comércio em grande escala, seja de produtos naturais, como a madeira, seja de terras em si,

somente a partir do Estado Novo, quando então a região saiu da negligencia governamental e da obscuridade política, recebendo o nome de Oeste Catarinense e, ademais, com o suporte de uma política nacional de aproveitamento dos seus recursos, que aqueles conflitos sobre a fronteira teriam cessado. Vamos perceber, pela análise a seguir, que esta conclusão precisa ser relativizada, tendo em vista que os conflitos se apaziguam não por força do Estado, mas pela pressão do mercado de capitais e pela coerção efetuada sobre os rebeldes em torno do trabalho, pressão estimulada pelas empresas que atuavam na região.

2 Diversos estudos, ao longo das duas últimas décadas quando a historiografia sobre a região do Contestado recebeu novas interpretações, apontam para o caráter cultural do termo caboclo para identificar o sertanejo, isto é, o natural do sertão. Cabe mencionar, evidentemente, que essa identidade é forjada a partir da alteridade desse sujeito diante dos que se autorrepresentavam como distintos ou não-caboclos: os citadinos, os civilizados, os portugueses, os colonos imigrantes europeus que se afirmavam, todavia, enquanto sujeitos que recusavam para si qualquer identificação com aquele grupo supostamente nativo dos caboclos. Entretanto, não era incomum encontrar entre os próprios caboclos ou sertanejos do Oeste a presença de imigrantes europeus, trabalhadores urbanos em busca de oportunidade e outros sujeitos que, a princípio, recusariam a identidade de caboclo ou sertanejos. (Cf. LAZARIN, 2005, para uma abordagem dos hibridismos materiais, cf. LINO, 2012). 
enquanto mercadoria fundiária e propriedade privada. Ao longo da análise do material que recolhemos, de todos os sujeitos históricos por nós considerados no contexto da Guerra do Contestado, seriam justamente os caboclos quem teriam uma subjetivação com a terra mais diversa e plural e, nesse sentido, mais complexa de se interpretar naquele contexto. Voltaremos a esse ponto mais à frente.

Outro ponto importante a ser ressaltado neste momento é a ideia de vocação agrícola atribuída ao Brasil no contexto da primeira República (1889-1930). Nessas décadas, diversos Estados da federação tentavam puxar a atenção para si na disputa pelos investimentos públicos, tais como a construção de ferrovias e de linhas de transporte urbano para a população, mas sobretudo para o escoamento de mercadorias produzidas no campo, a criação de linhas de crédito para 0 investimento em mão de obra imigrante e assalariada e, não menos importante, o devido suporte jurídico para os procedimentos legais na validação de compra e de venda de terra, além da comprovação dos títulos de propriedade. Esses diversos interesses modernizantes se combinavam bem com as tentativas de atrair os investidores estrangeiros para tornar a terra do sertão produtiva, ou melhor, um empreendimento lucrativo. Outro não foi o caso do sertão catarinense. Para se ter uma ideia, em editorial de 1919, o jornal $A$ república, publicado em Florianópolis, trazia o seguinte texto:

Duas notícias altamente enobrecedoras ambas para S. Catarina trouxeramnos do Rio os fios telegráficos. Uma que só indiretamente nos afeta, nem por isso deixa de ser, para nós especialmente, tam significativa e tam fora dos tempos de hoje que não nos furtámos ao prazer de a aludir e comentar. E ainda assim nos rejubila a prova de lealdade que o sr. Rui Barbosa deu ao seu vencedor considerando-se lealmente vencido no pleito e aconselhando os seus amigos a prestar apoio ao sr. Epitacio Pessoa de cujo governo a nação deve muito esperar. A outra porém, de ordem inteiramente diversa nos fala mais diretamente ao coração, nos alégra e nos comóve porque é a prova que aqui se trabalha e se vive e se progride. $\mathrm{O}$ mostruário dos productos catarinenses na exposição conquistou do sr. Vicepresidente da República francos e calorosos elogios e a S. Catarina foi conferido um destacado logar entre os estados essencialmente agrícolas. Isto revêla o desvélo com que o sr. Hercilio Luz segura as rédeas da governança do Estado impulsionando, de todas as maneiras, todas as atividades para tornar S. Catarina preeminente no concerto dos Estados do Brasil; e ai temos uma prova na afluência de capitais, que a todo momento, procuram se despejar pelos nossos campos e matas. Organizam-se companhias colonizadoras e os capitalistas estrangeiros enviam à $\mathrm{S}$. Catarina os seus representantes. (A REPÚBLICA, 17 de julho de 1919). ${ }^{3}$

\footnotetext{
${ }^{3} \mathrm{O}$ texto original foi mantido sem alterações.
} 
Com a criação das federações na República, as terras devolutas passaram para o domínio do Estado federativo, assim como passavam também para estes a administração na cobrança de impostos sobre propriedade, profissões e indústrias, além da legislação eleitoral e do direito no reconhecimento legal dos proprietários de terra e, por conseguinte, das terras que poderiam ser consideradas devolutas, isto é, sem cultivo ou inexploradas. Foi neste contexto, ainda na primeira década republicana, em que os conflitos de limites entre os estados do Paraná e de Santa Catarina se acirraram e, simultaneamente, que se iniciou um avanço na especulação fundiária promovida pelos investidores estrangeiros e empreiteiros do Estado. Por meio dessa ação, foi disponibilizado um conjunto de terras consideradas devolutas para o mercado de capitais. O que era de uso comum ou, simplesmente, terra sem dono, foi transformado em mercadoria fundiária.

Além disso, chefes políticos, coronéis e fazendeiros da região encontraram em meio a essas diversas disputas sobre a terra um cenário no qual poderiam se beneficiar econômica e politicamente, seja por meio da exploração de terras e na extração de madeiras, seja por meio de compadrios e benefícios privados a serem negociados junto à máquina pública. De acordo com Marlon Brandt (2009), este contexto "assinala a intensificação de diversas transformações socioespaciais na região do planalto de Santa Catarina, relacionadas principalmente à questão da terra, dando origem a diversas situações de disputa pela sua posse, sendo um dos vários motivos que levou a deflagração da Guerra do Contestado" (BRANDT, 2009, p. 4-5). A seguir, passaremos a analisar as relações de subjetivação com a terra que os principais grupos envolvidos no conflito desenvolveram naquele contexto. Iremos trabalhar com quatro grupos: os coronéis, os militares, os empresários estrangeiros e os caboclos.

\section{OS CORONÉIS}

Em seu clássico estudo sobre o coronelismo no Brasil publicado em 1948 sob o instigante título Coronelismo, enxada e voto, Victor Nunes Leal (1975) apresentanos a seguinte tese: o coronelismo é um sistema político que tem início com a decadência do poder exclusivo dos fazendeiros sobre uma região e se relaciona com a expansão do poder do Estado, no início da República, quando são criados 
poderes territoriais autônomos com as federações. Para Nunes, ao substituir o centralismo monárquico pelo federalismo republicano, surgiu um novo ator político importante e com amplos poderes no cenário brasileiro, o governador de Estado. No antigo sistema monárquico, o presidente da Província não possuía autonomia em relação ao Imperador, já que não detinha poder próprio e poderia ser removido a qualquer momento por decisão do poder central. Nesse sentido, a sua manutenção política dependia muito mais da sua proximidade com o poder central do Imperador do que com a população local que ele supostamente representava e para quem governava. No sistema federativo da República, por oposto, o governador era eleito a partir das suas relações com a sua base local ou regional. Assim, a sua manutenção política estava vinculada aos diversos atores que se multiplicavam nas hierarquias sociais no interior do Estado e inferiores a ele. Em especial, os chefes locais e territoriais, também chamados coronéis, eram os seus principais aliados, os quais deveriam ser conquistados com promessas de cargos públicos e benefícios possíveis com a máquina estatal (LEAL, 1975).

Ainda que este conceito tenha se ampliado desde a publicação de $1948^{4}$, podemos entender que o coronelismo ao qual Nunes Leal se refere somente poderia se efetivar, em termos de contexto histórico, a partir do momento em que os Estados federativos apresentassem maior autonomia em relação aos poderes centrais da União e, ao mesmo tempo, em que os canais com as lideranças locais estivessem abertos para um universo de negociações. Não sendo nosso objetivo, no entanto, discutir a validade histórica do conceito de coronelismo para o problema que estamos abordando com a Guerra do Contestado, o fato de existir uma palavra para designar este sistema político baseado em práticas sociais e politicas de líderes locais no Brasil republicano demonstra a importância que essa figura, o coronel, desempenhou no campo das representações sociais brasileiras.

Com efeito, o coronel é uma palavra ainda hoje referendada, de modo geral, ao contexto em que a violência e o uso do poder pessoal de forma arbitrária para obter ganhos sociais ou políticos torna-se prática costumeira. Em se tratando de

\footnotetext{
4 José Murilo de Carvalho (1998) chama a atenção para as particularidades do conceito de coronelismo, como o entende Vitor Nunes Leal, diferenciando-o dos conceitos de mandonismo, aplicado para os potentados rurais em contexto mais amplo que o republicano, assim como para o conceito de clientelismo, compreendido como uma prática política de negociação privada sobre bens e serviços públicos do Estado.
} 
uma suposta realidade histórica do interior do país, esta representação ganha ainda mais peso e presença. De acordo com Paulo Pinheiro Machado, o poder de influência dos coronéis na região do planalto catarinense, onde ocorreu o conflito do Contestado, deu-se de modo particular. Com um eleitorado ainda reduzido, em razão do baixo índice de eleitores alfabetizados na região - vale lembrar que nas novas leis eleitorais republicanas o voto censitário havia sido substituído pelo voto dos alfabetizados - o poder dos coronéis incidia apenas indiretamente sobre os resultados eleitorais. Portanto, o principal prêmio do jogo político não estava nas eleições, mas em outro ponto. De acordo com aquele historiador, "principalmente para o planalto norte, nas regiões de Curitibanos e Canoinhas [...] muitas lideranças locais firmavam-se como tais sem ocupar quaisquer cargos públicos, mas exerciam seu poder e influência política pela quantidade de homens em armas que poderiam rapidamente mobilizar" (MACHADO, 2001, p. 88).

Além disso, Paulo Machado nos revela um dado novo sobre esse contexto, da segunda metade do século XIX, na região planaltina catarinense: alguns coronéis estendiam a sua influência sobre as cidades pequenas e médias, por meio dos jornais que eram por eles, direta ou indiretamente, financiados. Desse modo, esses coronéis, em alguns casos, organizados em torno dos próprios partidos republicanos regionais, tinham em torno de si, como que gravitando ao redor dos seus interesses, intelectuais e profissionais liberais que detinham com eles uma relação de compromisso, uma espécie de compadrio. Esse tipo de relação de compadrio passava, a princípio, fora da órbita do Estado e das eleições, pois encontrava-se firmado com as respectivas lideranças agrárias locais e regionais, os coronéis. Se essa relação revertia em algum ganho eleitoral para os coronéis e, por conseguinte, para os governadores, era porque estava baseada em um contexto mais amplo do que o puro interesse no ganho de voto em campanha eleitoral.

Portanto, sendo o coronel um título distinto da Guarda Nacional que não se confundia com o militar de carreira, a sua área de influência era relativamente autônoma em relação aos poderes instituídos, inclusive, em relação às eleições. Os jornais, a partir da publicidade dos interesses dos coronéis, se tornaram veículos importantes por meio dos quais os seus discursos ganhavam publicidade e se amplificavam em cidades e setores sociais em que a sua força não pareceria consensual. A Guerra do Contestado, contudo, colocou à prova esse tipo de força 
pública dos coronéis em Santa Catarina. O apelo dos jornais era uma arma poderosa por meio da qual os coronéis atacados pelos rebeldes, outrora seus subordinados, tentariam reverter a opinião pública a seu favor e, com isso, chamar a atenção das forças de repressão sobre os caboclos identificados como responsáveis pela rebeldia, a fim de reprimi-los e puni-los. Por meio dos jornais, os fazendeiros faziam circular os discursos empreendedores na região por meio do apelo ao discurso do trabalho, desmobilizando a força cabocla reunida em torno da terra comum. A chegada da modernidade, por meio das ferrovias e do aumento de exportação da erva-mate, era recebida como sinal da vocação agrícola de Santa Catarina, algo que deveria ser compartilhado com aqueles que trabalhavam para esse engrandecimento - logo, todos aqueles que não trabalhassem para tal sofreriam censura moral e poderiam ser perseguidos por se colocarem na contramão do esperado progresso nacional e catarinense. Desse modo, lemos o seguinte discurso no editorial de 13 de agosto de 1916, do jornal Imparcial, publicado no município de Canoinhas:

\begin{abstract}
O nosso município, pelas suas opulentas riquezas naturaes assás fáceis de serem exploradas, está fadado a occupar um logar de destaque na communhão catharinense. A herva-matte, ora cotada a ínfimos preços, é o seu único ramo de negócio, hoje. É o seu dinheiro, podemos dizer. É a roupa e o pão do povo. E, tão extensos e abundantes são os nossos hervaes, que, nem por isso, serão aproveitados, na presente safra, siquer pela terça parte. - Extensos, abundantes e de optima qualidade, basta esse inestimável thesouro, de futuro inegavelmente promissor, como seguro penhor d'aquella nossa asserção. Mas não se pense que a riqueza florestal d'este município paira nos seus hervaes, apenas; ahi estão, para attestar ao contrario, gigantescas imbuias e soberbos pinheiraes, que, em breve, hão de constituir um grande e lucrativo ramo da sua industria extractiva. (IMPARCIAL, 13 de agosto de 1916, n. 34).
\end{abstract}

Esse discurso de apelo modernizador não se fez circular sem oposições. Alguns coronéis, como Francisco de Albuquerque, influente na região de Curitibanos, e Fabrício Vieira, do Vale do Timborzinho, foram frontalmente atacados pelos sertanejos do Contestado devido às aproximações que fizeram junto aos setores extrativistas e madeireiros que, então, desapropriavam e especulavam a terra antes colocada sob os cuidados da população cabocla local. Pode-se perceber, nesse caso, que a terra para os coronéis, quando não era suficiente para garantir o voto no sistema eleitoral da República, garantia a influência na região de domínio sob a qual eles submetiam uma quantidade definida de homens sob o seu controle. Em outras 
palavras, foi a promessa de segurança da população sertaneja e a rede de compadrios que se estabelecia entre esses grupos com os coronéis o que permitira, por um tempo, a reciprocidade entre os subalternos e os coronéis. ${ }^{5}$ Uma vez colocado em perigo o elo que os vinculava - jogada na ficção do mercado a proteção sobre a terra antes garantida -, o compromisso entre caboclos e coronéis cessaria e o que antes era tomado como confiança e compadrio transformava-se em relação de revolta, inimizade e ódio.

Cabe registrar que as prédicas do Monge João Maria, passadas "como se fossem mandamentos para uma boa vida no sertão", baseavam-se "em valores como o respeito, a defesa da vida e da honra, a lealdade, a sinceridade e o equilíbrio" (MACHADO, 2001, p. 91). Transcrevemos abaixo um trecho desse discurso:

\author{
Se tu for um camarada \\ Zele tudo do patrão \\ Trabaiando com respeito \\ Cuide bem da obrigação \\ Sendo dono ou encarregado \\ Da fazenda ou da empreitada: \\ Operário é como filio \\ Cuida bem dos camaradas (apud MACHADO, 2001, p. 92).
}

Nessas estrofes são "colocadas as obrigações mútuas entre patrões e empregados" (MACHADO, 2001, p. 92), sinalizando o laço de reciprocidade que existia entre eles, inicialmente, firmado a partir da esperada segurança do trabalho e da ocupação da terra, regras de comportamento que deveriam ser observadas pelos dois lados da relação. Contudo, na medida em que os coronéis avançaram com os seus interesses e a sua nova rede de alianças com os diversos empreiteiros, sobretudo, os estrangeiros que desconheciam e ignoravam o vínculo de sobrevivência mantido pelos sertanejos com a terra, aquela antiga relação de reciprocidade se enfraqueceu e passou a ser substituída pelo signo da desproteção

\footnotetext{
5 "Com frequência, os fazendeiros eram padrinhos de batismo dos filhos dos peões e dos agregados, o que os tornava compadres dos seus empregados. Para os trabalhadores sertanejos o batismo significava, principalmente, um meio de proteção da criança, já que, pela tradição católica, o padrinho é um segundo pai, ou um pai espiritual, podendo assumir responsabilidades na educação e proteção ao afilhado. Nesta logica, quanto mais poderoso o padrinho, melhor. Para o fazendeiro, apadrinhar uma criança significava assumir um conjunto de compromissos ligados ao auxílio para o afilhado, mas recebendo, em contrapartida, a lealdade tanto do afilhado como de seu compadre. Pela tradição do planalto, a relação entre compadres e comadres implicava em atitudes de auxílio, respeito e numa espécie de extensão dos laços familiares" (MACHADO, 2001, p. 52-53).
} 
e da traição. Sem a segurança prometida da terra, os coronéis perdiam também a sua rede de subalternos. ${ }^{6}$ Nesse sentido, sob a perspectiva dos coronéis, a terra se fazia representar como um laço político por meio do qual era possível conquistar (ou não) uma rede de influência e garantir que o seu poder, no interior dessa rede, fosse respeitado e se exercesse livremente. Uma vez comprometido o elo de segurança com a terra, o poder a ela vinculado também era abalado e se desfazia.

\section{OS MILITARES}

A disputa em torno da terra, na região do Contestado, era percebida de uma maneira absolutamente distinta pelos grupos militares ali envolvidos. Cabe situar que os militares, de modo geral, se dividiam em rígidas hierarquias internas à sua corporação. Essas hierarquias representavam posições assimétricas no envolvimento com o conflito: de um lado, os indivíduos que ocupavam posições mais vulneráveis no conflito, os soldados, e de outro os chefes militares, líderes estrategistas que ocupavam uma posição superior menos vulnerável em campo. Esse grupo superior não apenas se apresentava habilitado para o enfrentamento direto contra os rebeldes, como demonstrava, por meio de artigos enviados para a imprensa das cidades e dos seus registros em diários de campo, uma certa predileção pela reprodução intelectual e escrita do conflito travado braço a braço. São pelas mãos dos militares que temos hoje a oportunidade de interpretar a Guerra do Contestado pela ótica das forças armadas de segurança nacional. Que fique registrado, porém, que outras pesquisas precisariam suprir esse vazio, em torno das subjetividades militares no conflito, para nuançar o que vamos analisar a seguir.

A terra para o grupo militar era representada como fronteira (LIMA, 1999; ARAUJO, 2008). Essa fronteira, durante o conflito, poderia ser entendida sob um plano geoespacial de divisão de territórios. Após o conflito, porém, essa fronteira

\footnotetext{
6 "O poder dos fazendeiros sobre seus peões e agregados se baseava na propriedade sobre a terra e no poder de ceder, em situação precária, como uma 'favor', uma capoeira para o agregado fazer sua pequena roça. Por outro lado, o poder do peão ou agregado sobre o fazendeiro também existia, uma vez que era cada vez mais difícil contar com um camarada leal e trabalhador, principalmente com uma fronteira agrícola em expansão tão próxima, como em Curitibanos e Canoinhas. Nestas regiões, os peões e os agregados tinham várias opções. Paralelamente, um conjunto de laços de lealdade e reciprocidade constituíam-se através de relações de compadrio. Quando as propriedades eram vendidas este pacto tinha que ser refeito com o novo proprietário, o que não era incomum" (MACHADO, 2001, p. 93-94).
} 
passaria a ser interpretada também pelos aspectos sociais, "bárbaro" e "selvagem", que eram atribuídos aos sertanejos do Oeste. Uma fronteira que se colocava, em um primeiro momento, espacialmente, mas que à medida que o conflito ia avançando e, mais ainda, após o seu término, se radicalizava culturalmente como limite de uma divisão entre um "eles" e um "nós". Nessa perspectiva, fronteira que buscava demarcar entre os seus limites a presença de um Outro. Sobretudo em relação às crenças religiosas, a perspectiva militar opunha-se radicalmente aos discursos das lideranças populares do Contestado, designando a população das "Cidades Santas" como uma verdadeira "massa de fanáticos". Nas palavras de um oficial da época, Herculano D’Assumpçãon (apud BRANDT, 2009, p. 3), era preciso:

incentivar a instrucção primaria naquelles sertões e estimular os seus habitantes aos trabalhos da lavoura e da industria pastoril. [...]. É necessário encaminhar para o bem os homens madraços que alli habitam e preparar, pela educação, as novas gerações sertaneja que ora surgem.

O projeto de civilização encarnado pelas vitórias militares era o principal valor atribuído à terra naquela região. Analisando os diários dos militares, Marlon Brandt (2009, p. 6, grifos do autor) é quem nos oferece a interpretação:

Em geral, o que se percebe a partir da leitura desses textos, é que o futuro da região dependia da transformação das "intermináveis florestas" e campos em territórios "civilizados", onde "o caos da floresta sucumbisse à ordem, à racionalidade, à agricultura, considerada um símbolo da presença e da engenhosidade do homem civilizado. A natureza deveria ser subserviente ao homem".

Este tipo de valor militar sobre o sertão, região considerada atrasada e bárbara, de natureza frondosa, porém inculta, não foi característica unicamente dos militares em expedição na região do Contestado, mas reincidente em outros conflitos vinculados à terra no interior do Brasil. Em Canudos, durante as campanhas militares de 1895 a 1897, o exército da República que marchava em direção ao povoado baiano ocupado pela população sertaneja, que tinha com o líder beato Conselheiro uma relação de obediência e adoração, acreditava que as crenças fanáticas existentes ali deviam-se ao isolamento geográfico e à relação imediata que aquela população inculta desenvolvia com a terra. Euclides da Cunha, por exemplo, chegou a afirmar que o sertanejo representava em seu corpo a tragédia da seca do sertão. Tais como seres de uma sociedade natural, como "centauros broncos" 
preparados para a batalha da vida em ambiente inóspito e trágico criado pela seca, os sertanejos estariam vinculados ao natural, ao "imediato da terra", mas também a uma forma pouco especializada e praticamente primitiva de dominação - dominação evidenciada pela presença e obediência a um líder místico, medievo e carismático (BACH, 2011). Para Euclides - um militar extremamente intelectualizado formado para a defesa da República - o sertanejo era como uma "perfeita tradução moral" do seu meio e desenvolvia com a terra uma verdadeira relação vital, já que ele

[...] atravessa a vida entre ciladas, surpresas repentinas de uma natureza incompreensível, e não perde um minuto de tréguas. É o batalhador perenemente combalido e exausto, perenemente audacioso e forte; preparando-se sempre para um recontro que não vence e em que se não deixa vencer; passando da máxima quietude à máxima agitação; da rede preguiçosa e cômoda para o lombilho duro, que o arrebata como um raio pelos arrastadores estreitos, em busca das malhadas. Reflete, nestas aparências que se contrabatem, a própria natureza que o rodeia - passiva ante o jogo dos elementos e passando, sem transição sensível, de uma estação à outra, da maior exuberância à penúria dos desertos incendidos, sob o reverberar dos estios abrasantes. É inconstante como ela. É natural que o seja. Viver é adaptar-se. Ela talhou-o à sua imagem: bárbaro, impetuoso, abrupto... (CUNHA, 2001, p. 214- 215).

Menos conhecidos que os escritos de Euclides, os exemplares literários e fotográficos dos militares que estiveram em expedição durante o conflito na região do Contestado também se assemelham ao seu gênero e perspectiva sobre Canudos. Em certa medida, Euclides ditava ali certa fonte de inspiração para o registro desses militares posteriormente (BRANDT, 2009). Demonstrando um ceticismo em relação aos conflitos que ali em Santa Catarina surgiam, o oficial Demerval Peixoto (apud BRANDT, 2009, p. 3) dizia, agora em 1920:

[...] a região contestada esteve sempre e se eternizará entregue ao despotismo dos chefetes locais, ao desvario de uma sorte inumerável de crimes mal apurados e ao desmando de caudilhos temíveis, homiziados, fora da alçada da justiça das cidades; e tais têm sido os propulsores morais das causas que levaram à rebeldia, como recurso de defesa, os sertanejos ignorantes e espoliados pelos prepotentes.

Como no discurso do Capitão Vieira da Rosa que atestava "a existência de uma natureza exuberante, com 'mattas soberbas' e 'pastagens riquíssimas', onde 'com um pouco de boa vontade dos dirigentes aquellas terras que quasi todas são ainda posses apenas, poderiam tornar-se de uma produtividade espantosa'" (apud BRANDT, 2009, p. 7), a crítica aos hábitos produtivos do Contestado é 
continuamente levada a cabo pelos militares. Nesse caso, nem os fazendeiros são poupados dessas críticas, considerados indolentes e pouco empreendedores nos negócios do campo. Esta crítica aparece na palavra do Capitão Vieira da Rosa (apud BRANDT, 2009, p. 8):

Em geral, o fazendeiro, em dolce farniente, fica em casa e deixa o gado entregue à natureza. Somente uma ou duas vezes no anno é ele recolhido às mangueiras para a salgagem [sic], ocasião em que é feita a marcação. Esta é constituída de arabescos ou de iniciais dos fazendeiros.

A perspectiva dos militares sobre a terra no conflito se aproxima do projeto de civilização da República (LIMA, 1999). Nesse tipo de compreensão sobre a terra, o interior do Brasil era representado como ambiente dominado por crenças bárbaras, forças retrógadas que deveriam ser instruídas ou, se e quando resistentes, superadas para que se pudesse abrir passagem para o moderno, enfim, ali no sertão se instalar. A terra, nesse sentido, se torna um lugar de fronteira, símbolo da travessia na qual a civilização deveria avançar e cruzar para levar o esclarecimento e os hábitos modernos para aquela região e sua população. Em certo sentido, os militares se autodeclaravam os missionários dessa missão civilizatória e pedagógica sobre o sertão, terra de natureza selvagem, mas que deveria ser controlada, estudada e, por fim, melhor aproveitada também pela sua gente, para os ganhos da riqueza nacional.

\section{OS EMPRESÁRIOS ESTRANGEIROS}

$\mathrm{Na}$ análise anterior, encerramos a concepção de terra registrada entre os militares que lutaram na Guerra do Contestado como marcada pelo signo da fronteira. Em realidade, para os militares, a terra não apenas representava a fronteira entre o atraso e progresso, mas, também, era interpretada como fonte de riqueza e de crescimento da nação. Se a riqueza era tomada em sua apropriação nacional, lidaremos a partir de agora com uma perspectiva absolutamente oposta com o discurso dos empresários estrangeiros. Para essa análise, levaremos em consideração a maior e principal agência de investimentos daquele período na região do Contestado, a Brazil Railway Company. A empresa foi fundada em 1906, nos EUA, pelo empresário Percival Farquhar (1864-1953), magnata operador de 
Wall Street "responsável por levantar capital na Europa para a organização da empresa, com a colaboração de banqueiros ingleses, franceses e belgas" (CARVALHO, 2010, p. 223). O objetivo de Farquhar era o de concluir a estrada de ferro que ligava São Paulo ao Rio Grande do Sul e melhorá-la tecnicamente, de forma a integrar o sul do continente por meio da expansão de ramais ferroviários que ligariam São Francisco do Sul, Foz do Iguaçu, Assunção (Paraguai) e Antofagasta (Chile). Sua ambição no continente americano reproduzia, no cone sul, um modelo já experimentado pelo seu escritório nos EUA.

Para se ter uma ideia da dimensão da atividade empresarial de Farquhar no Brasil, seus negócios com a Brazil Railway Company não permaneceram restritos à construção daquela linha de trem. Como um conglomerado de outras empresas, a Brazil Railway Company atuava, além da construção de ferrovias, também na modernização dos portos, na criação de fazendas de gado e frigoríficos, na exploração de madeiras e serrarias, bem como no setor hoteleiro ${ }^{7}$. Logo, torna-se importante atentar para a ampla rede comercial e de mercado de capitais que o empresário norte-americano Percival Farquhar representava no contexto de Santa Catarina e do Brasil.

Uma vez na região, Farquhar buscou contratar engenheiros estadunidenses de confiança, experientes no ramo da construção de estradas de ferro, bem como engenheiros e, especificamente, advogados brasileiros, como Geraldo Rocha. Sendo então de sua propriedade a maior serraria da América Latina, naquele momento, localizada em Três Barras no planalto norte catarinense, região de litígio no conflito entre os Estados do Paraná e de Santa Catarina, Farquhar buscou se antecipar dos possíveis litígios que dali decorreriam, contratando os melhores

\footnotetext{
${ }^{7}$ De acordo com o historiador Miguel de Carvalho: "Entre as empresas subsidiárias da Brazil Railway criadas por Farquhar está a Southern Brazil Colonization Company (mais tarde Brazil Development and Colonization Company), destinada a tratar da administração das terras concedidas pelo governo brasileiro próximas à ferrovia, além da colonização/venda de lotes a pequenos agricultores. Outra empresa subsidiária criada por Farquhar era a Brazil Land, Cattle and Packing, que adquiriu cerca de 32 mil km² em terras (cerca de $0,4 \%$ da área total do país) e 200 mil cabeças de gado, num total de 5 fazendas localizadas em Mato Grosso e em Minas Gerais. [...] Em se tratando de ferroviais, a Brazil Railway era não menos impressionante em termos de gigantismo. Controlava uma série de linhas em São Paulo, Paraná, Santa Catarina e Rio Grande do Sul, como a Estrada de Ferro São Paulo - Rio Grande e seus ramais, a Tereza Cristina (na região carbonífera de Santa Catarina), a Auxiliaire (no Rio Grande do Sul), a Estrada de Ferro Norte do Paraná e a Sorocaba. Segundo o engenheiro Frederick A. Molitor, a Brazil Railway em 1913 controlava $6.090 \mathrm{~km}$ de linhas, o que equivalia a $25 \%$ das ferrovias do país e a $56 \%$ das ferroviais dos três Estados do Sul mais São Paulo" (CARVALHO, 2010, p. 224).
} 
profissionais do direito naquele momento (com quem ele ganharia prestígio na região) e se cercando de "uma grande rede de relacionamentos e contatos que o ajudava a escolher a dedo os seus colaboradores" (CARVALHO, 2010, p. 226).

Um dos colaboradores de Farquhar na serraria de Três Barras foi Frank S. Pearson, profissional com experiência no ramo das madeireiras, tendo sido responsável pela construção de serrarias no México nesse mesmo período em que se erguia 0 conglomerado de Farquhar no Brasil $^{8}$. Ressalte-se, porém, que a concessão da construção da ferrovia São Paulo - Rio Grande data de começo de novembro de 1889, dias antes da queda do regime monárquico e proclamação da República no Brasil. O administrador nessa época era o engenheiro brasileiro João Teixeira Soares, que adquiriu a concessão sob a garantia de juros fixos, por 30 anos, e o direito à exploração de terras devolutas em até $30 \mathrm{~km}$ nas margens das linhas. Somente em 1906, após uma série de decretos e mudanças nas leis de concessões, que a Brazil Railway Company adquiriu os direitos da construção e, com eles, os benefícios já previstos anteriormente para João Teixeira Soares.

A construção da estrada de ferro era o principal objetivo da companhia. Entretanto, conforme arquiteta Farquhar, em carta para Vivaldo Coaracy, (Rio de Janeiro, 9 de março de 1943 apud CARVALHO, 2010, p. 232):

A maior parte das terras sobre as quais a Brazil Railway Company tem direitos no Estado do Paraná e Santa Catarina está coberta com florestas de pinho e outras madeiras. Estas terras devem primeiro ser desmatadas para que elas possam ser cultivadas, e esse desmatamento vai, em si mesmo, ser uma fonte de lucro considerável.

O plano de desenvolvimento elaborado pelo grupo da Brazil Railway Company, em sua subsidiária madeireira, a Southern Brazil Lumber Company, não apenas desconsiderava a relação vital que as populações sitiantes apresentavam com a terra, como transformava a terra em mercadoria colocada à venda ou especulada para a produção de capital, isto é, produto de "lucro considerável". Da criação da Lumber, em 1908, ao funcionamento da serraria de Três Barras, em 1911,

\footnotetext{
8 "Pearson, a exemplo do seu colega [Percival Farquhar], comprou terras ricas em madeira e pastos e construiu serrarias no alto da Sierra Madre Ocidental, na província de Chihuahua, México. Da mesma forma, as serrarias de Pearson foram destruídas pelas 'hordas de Pancho Villa' em princípios da década de 1910, portanto, mais ou menos na mesma época em que os rebeldes do Contestado destruíram a serraria Lumber em Calmon. Essa coincidência sugere o quão complicados eram os planos mirabolantes de empresários totalmente alheios aos contextos locais onde pretendiam desenvolver seus negócios" (CARVALHO, 2010, p. 227).
} 
“a empresa comprou uma série de fazendas no planalto do Contestado e na região dos campos gerais do Paraná, cujas terras tinham sido todas legitimadas pelos antigos proprietários junto ao governo do Paraná", contando com "um praticamente inexaurível suprimento de madeira nas terras incluídas na concessão da São Paulo - Rio Grande" (Brazil Railway Report, 1910 apud CARVALHO, 2010, p. 233).

Em outro relatório do gerente da Lumber, Sherman Bishop, documento agora produzido após o conflito, no ano de 1917, lemos o seguinte discurso:

\begin{abstract}
Enquanto que eu devo admitir que Cachoeirinha tem concorrido com toda sua parte para augmentar os nossos lucros geraes e deve receber credito para a maioria da porcentagem, este não era o meu intento quando fazia o meu Relatório para o mez de Abril. O que eu desejava demonstrar era o que uma serraria daquelle typo poderia fazer em circumstancias ordinárias quando não está sobrecarregada com pezadas despezas de administração e geraes. Infelizmente para Cachoeirinha, enquanto ella precisa suportar a sua proporção de nossas despezas geraes, nossa intervenção não é necessária para o seu sucesso. [...] A serraria de Cachoeirinha foi construída para o fim de reforçar a posição da de Três Barras, e devo dizer que ella tem feito tudo o que podia esperar della (BISHOP, 1917, p. $4 ; 10$ ).
\end{abstract}

Fica-se com a impressão de que a serraria de Cachoeirinha pareceria, finalmente, "ter dado tudo" o que era possível em termos de lucro na extração de madeira. Para entender melhor este relatório, transcrevemos abaixo o outro relatório, agora do mês de abril de 1917, no qual a impressão que tivemos, enfim, se esclarece:

Com referência a propriedade de Vallões que consiste de títulos para os terrenos de Moças, Cruzes, Rio Preto, Vallões e Escada, e que contém, segundo os títulos um total 21.600 alqueires, estes terrenos custaram 700.133,59 francos e como a Linha de São Francisco da Estrada de Ferro passa por dentro dessa propriedade numa extensão de mais de cincoenta kilometros, as facilidades para operações são excellentes, visto que a Estrada de Ferro accompanha o rio Iguassú e as mattas estão situadas sobre o mesmo num planalto gradual, facilitando a puxada de toras. Esta propriedade contém no mínimo um bilhão de pés de madeira em toras para serra com uma boa porcentagem de imbuia que é de grande valor. $O$ valor do "stumpage" em taes condições desta qualidade seria muito barata á Rs. $1 \$ 500$ por mil pés o que importaria em 1:500\$000 mais ou menos. 0 solo é muito fértil e nas proximidades do rio lguassú não há logar melhor para a locação de uma prospera colônia. Nessa propriedade seria fácil a venda de lotes á $50 \$ 000$ por alqueire. Por ahi realizareis que esta propriedade é de grande valor e deverá ser retida á todo custo. Visto que é uma das propriedades das quaes esta Companhia depende em tirar maiores proveitos pecuniários. Recomendamos e temos as melhores intenções de, se formos autorizados, dividir o grande engenho de Três Barras e estabelecer duas serrarias nesta propriedade depois que 0 engenho de Três Barras cortar toda a madeira em Três Barras e vizinhanças. A propriedade de Vallões dista mais ou menos 100 kilometros do engenho de Três Barras, cuja distancia é muito grande para se pagar frete sobre as toras. Porém estes 100 kilometros addicionados ao nosso já 
longo percurso não importará em muito mais. Devido á excellência do pinho e imbuia nesta propriedade e a grande quantidade dos mesmos, derivaremos um lucro extraordinariamente grande de operações alli. Estas mattas são as únicas que receberão a vantagem da abertura da nova linha entre Canoinhas e Porto da União. Enquanto as outras serrarias pequenas tem suas mattas diminuídas e o percurso de transporte mais longo cada anno para a conducção de suas toras por meio de cavallos e gado, e seu custo de producção augmenta cada anno, ao passo que o nosso custo por muitos annos depois de nos estabelecermos nessa propriedade será o mínimo e poderemos syndicar o mercado de madeira no Brasil. [...] $\mathrm{O}$ terreno em Cachoeirinha é de muito boa qualidade e poderá ser vendido por um preço maior do que pagamos mesmo depois de ter removido a madeira (BISHOP, 1917, p. 1-2; 10).

Após a exposição dos pontos positivos na divisão da serraria de Três Barras e na exploração de madeiras em Cachoeirinha, a conclusão a que se chega neste relatório da empresa de Farquhar é a de que a terra, sob a sua perspectiva, não apresentava outro valor a não ser o de mercadoria e, mais ainda, como produtora de capital e oportunidade para o lucro. Um sentido absolutamente comercial e capitalista sobre o conceito de terra e, de maneira geral, de natureza, vista como uma fonte de recursos a serem explorados e disponibilizados para o mercado. Se por um lado, assim como os militares, a terra sinalizava uma promessa de riqueza, por outro lado, diferente dos militares, essa riqueza não seria prova da grandeza nacional, mas sim dos investimentos empresariais de agentes estrangeiros sobre os recursos da terra na região.

\section{OS CABOCLOS}

Passamos em análise, até agora, os discursos dos principais sujeitos implicados com a Guerra do Contestado. Analisamos o modo como os coronéis, os militares e os empresários estrangeiros se subjetivavam com a terra, isto é, a partir de quais valores eles interpretavam o conceito de terra no contexto da Guerra do Contestado. É chegado o momento, agora, de nos voltarmos para o principal grupo envolvido no conflito, os caboclos sertanejos. Embora apenas aparentemente evidente, esse sujeito apresenta uma heterogeneidade social de valores que torna, enfim, a sua representação da terra em uma teia complexa de valores. ${ }^{9}$

\footnotetext{
${ }^{9}$ Por do meio da análise das memórias dos sobreviventes e dos testemunhos dos remanescentes vivos do conflito, Paulo Pinheiro Machado nos apresenta um perfil muito mais matizado do grupo dos caboclos sertanejos da Guerra. Os testemunhos servem para compreender o período mais brutal da Guerra, de 1914 a 1916, quando o recrutamento armado, tanto para o lado das forças repressoras do
} 
Márcia Espig (2007) levanta este tema ao analisar a trajetória do general militar Fernando Setembrino de Carvalho na Guerra do Contestado, que se colocou durante uma parte do conflito, supostamente, na missão de captura e prisão aos exoperários das empresas de Farquhar, em especial, operários da Estrada de Ferro São Paulo - Rio Grande. Para a autora, o que se denomina genericamente como "rebeldes" é composto por um grupo bastante heterogêneo: "sertanejos e caboclos que habitavam tradicionalmente a região, imigrantes chegados há pouco, migrantes de zonas próximas, bandidos que buscavam guarida na região pouco policiada" (ESPIG, 2007, p. 200). Essa heterogeneidade torna ainda mais complexa a tarefa de compreender a subjetivação dos caboclos pela terra. Nesse sentido, tentaremos apresentar alguns dos seus valores possíveis, mesmo sabendo que, justamente, devido à heterogeneidade do grupo, as suas percepções se apresentam, para nós, por demais diversas. Em realidade, exatamente por meio da dispersão que poderemos iniciar o entendimento da sua relação com a terra.

Devemos, primeiro, matizar as características desse grupo. Para os caboclos, de modo geral, a ordem natural da floresta se relacionava com a ordem social e a busca pela vida, de modo que a fusão entre os três vetores, floresta, sociedade e cuidados com a vida e sobrevivência, os colocavam em um contexto absolutamente distinto em relação aos demais sujeitos históricos em luta ali no conflito do Contestado. Por muito tempo, esse vínculo entre natureza e ordem social foi interpretado pela literatura sociológica e historiográfica como sendo de uma matriz mais ampla, presente nos movimentos sociais desse período da República, comumente chamados de movimentos messiânicos. Considerando a natureza como uma entidade sagrada para os sertanejos, oferecida para o trabalho do homem sobre o solo, de onde ele tiraria o seu sustento de vida, a ordem social que daí se

governo quanto para o lado dos caboclos nos redutos, criava cisões internas dentro do próprio grupo dos sertanejos. Segundo Maria Conceição Correia (apud MACHADO, 2011, p. 179), filha de um pequeno fazendeiro de Canoinhas: "Por aqui os jagunços viviam iludindo e enganando as pessoas para elas irem ao reduto. Alguns foram assim; foram convencidos. Outros foram levados à força. Eu lembro que morava aqui em Canoinhas, a cidade foi atacada, minha família teve que fugir de um sítio aqui perto, com a roupa do corpo. Fugimos para o Paraná e só voltamos no final da guerra. Isto aconteceu quando eu estava com meu pai e minha mãe debulhando milho em nosso sítio. Ouvimos um barulhão, eram os jagunços atirando e dando 'vivas' Os jagunços queriam levar meu pai. Mas minha mãe deu gado e muito sal para os jagunços não levarem o meu pai. Quem não obedecesse à ordem dos piquetes dos jagunços, eles matavam. Foi minha mãe quem salvou nossa família, ela não deixou os jagunços levarem o meu pai, não deixou o pessoal do governo levar meu pai também. Naquele tempo o governo também pegava gente à força para virar soldado". 
organizaria também levaria em conta esta relativa identidade entre a terra e 0 trabalho da vida do sertanejo. Essa interpretação de matriz messiânica que se tem feito sobre o caboclo subordina a natureza aos valores sociais do trabalho, da posse e da produção da vida orientados por crenças religiosas (AURAS, 1984). Tentaremos buscar, agora, uma outra interpretação para essa relação entre natureza, sociedade e trabalho entre os sertanejos do Contestado.

Em depoimento dado em 11 de fevereiro de 1998 para o historiador Paulo Pinheiro Machado, Antônio Fabrício das Neves, um filho dos redutos, nos apresenta uma interessante reflexão sobre a relação entre natureza, ordem social e manutenção da vida na região do Contestado. Perguntado, por Paulo Pinheiro Machado, sobre o suposto fanatismo do monge José Maria e seus seguidores e redutos, Fabrício discursa:

Não. Isso aí é o que eles (os inimigos) queriam dizer para desacreditar o homem. Queriam dizer que ele estava mentindo. Que ele se dizia ser um santo, eu nunca ouvi dizer que alguma vez ele falou isso. Ele dava os pareceres dele, mas dentro de um ritmo de futuro, de respeito, de gente que queria crescer junto. Por isso é que essa gente de Curitiba veio aqui dizendo que era o tal fanatismo, que ele nunca pregou, nunca defendeu. Eram os de fora que chamavam de fanáticos, e principalmente os de fora que se interessavam por esse pedaço de terra. Que eles estavam se preparando para o que aconteceu hoje. Porque se não fosse esse combate deles aí, onde muitos entregaram a vida, nós não estaríamos aqui agora. Quem defendeu os catarinenses, quem defendeu o Estado de Santa Catarina, foram esses três homens (José Maria, Fabrício e Fragoso). Defender esta terra, este era o ideal deles. Como diz o verso:

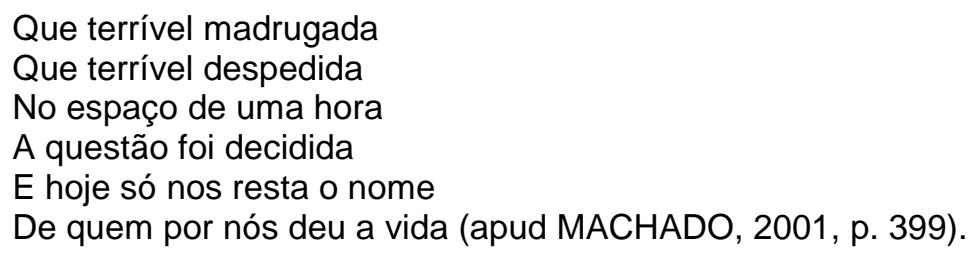

De modo geral, a terra aparece representada entre os discursos relacionados a esse grupo através da experiência de vida que ela permite organizar. Isto é, não seriam propriamente aspectos econômicos ou tampouco religiosos que vinculariam os caboclos à terra, mas uma certa percepção de que ali seria o lugar onde essa população se encontrava e poderia fabricar e defender a sua vida. Esse tipo de vínculo de vida, por nós ressaltado, pretende afirmar a relação ontológica, estabelecida pelos caboclos, que remete para um sentido de elo vital entre eles com a terra. Em certa medida, a terra é o elemento que organiza a vida nas cidades do 
Oeste. A partir dela podem se somar outros vetores, como a religiosidade, o poder político, a ordem da natureza, no entanto, devemos nos atentar para o valor de que ali a terra - na sua existência enquanto entidade inescapável que permite que outros aspectos (religiosos, políticos, econômicos) se desdobrem sobre o seu signo aparece relativamente autônoma e faz com que a representação de natureza se associe a uma representação de identidade com a própria vida.

Deve-se atentar que esta postura vai de encontro e opõe-se ao argumento clássico, de messianismo, que interpreta o conflito dos caboclos no Contestado. Marli Auras (1984) nos explica que após todas as tentativas de resistência e entendimento lançadas sobre o mundo em radical transformação à sua frente, os caboclos sertanejos encontraram na religiosidade messiânica a construção ideológica adequada, onde o mundo poderia finalmente se organizar. Desse modo, a autora compreende "o momento de criação da visão de mundo norteadora do movimento rebelde - a construção da irmandade - aglutinador de considerável número de sertanejos" (AURAS, 1984, p. 4).

Ainda que Marli Auras se coloque junto aos documentos produzidos pelas comunidades caboclas, de modo a perceber que a organização dessas comunidades não foi feita a priori, mas sim a medida em que o conflito na região se agravava e se desenvolvia, a sua interpretação apresenta a religiosidade dos redutos como resultado de união cabocla sobre a terra. Em realidade, nossa interpretação é a de que uma vez desprotegidos ou, quando menos, inseguros em relação à proteção dos "grandes" (coronéis, leis do Estado) sobre a sua fixação na terra, os caboclos sertanejos que trabalhavam na terra especulada e vendida, pelo governo e com o aceite dos coronéis, tornaram-se desconfiados em relação aos reais compromissos desses dois agentes. Além disso, o estímulo ao uso da mão de obra imigrante europeia, então, avulsa na região, tornava a relação entre os caboclos e os seus protetores bastante confusa. Esta relativa confusão tomava lugar imediato sobre a ocupação da terra. Em depoimento para Paulo Pinheiro Machado, Gilberto Kopecki, filho de Ana Júlia Kopecki (apud MACHADO, 2011, p. 180),

[...] imigrante de origem polonesa que escrevia rezas para os sertanejos do reduto de Bonifácio Papudo, [...] lembra que a Brazil Lumber and Colonization Co., empresa norte-americana, subsidiária da Brazil Railway, encarregada da exploração da madeira e da colonização com imigrantes dos territórios marginais à estrada de ferro São Paulo-Rio Grande, usava de 
força, fraude e constrangimento político para expulsar os antigos moradores da região: "Em alguns lugares tiravam à força mesmo, com capangas. Em outras situações eles obrigavam o pessoal a assinar um papel em branco. Quem fez isto aqui foi o Nereu Ramos, que era advogado da Lumber. O Nereu, mesmo novo, tinha muita autoridade sobre as pessoas, era filho do Governador Vidal. Ele reuniu o pessoal dizendo que era para assinar em branco os papeis, que todos iam ter suas terras regularizadas. Que nada! As assinaturas serviam para as pessoas renunciarem ao direito de posse, isto minha mãe viu pessoalmente, aconteceu mesmo" .

Nosso argumento, nesse sentido, investe em um aspecto mais fragmentado e singular sobre a suposta união dos caboclos aparentemente reunidos em frentes comuns sobre a terra. Suas lutas se davam não puramente porque eles compartilhavam de uma visão de mundo religiosa comum, mas porque a dispersão e a desconfiança que os caracterizavam poderiam se ver representadas, naquele momento, na respectiva percepção sobre a terra livre com a qual eles pretendiam trabalhar. Como um horizonte aberto ou um pedaço de chão, a terra livre permitia que a dispersão do sertão conciliasse uma miríade de indivíduos em seus diversos e limitados interesses em um mesmo processo de subjetivação. A ausência de leis de terras efetivamente aplicadas, no contexto anterior ao conflito, deu ensejo para que uma diversidade de singularidades se processassem, a partir daí, naquela região planaltina vinculando-se, justamente, a sua massa trabalhadora ao apego à terra.

Para situar um exemplo que escapa do esquema messiânico de unidade sertaneja em torno da terra, consideremos os processos de regularização fundiária produzidos entre os anos de 1890 e 1910 no município de Lages. Nesses processos, a fim de garantir o título de propriedade para aqueles que se encontravam em uso por posse, a terra aparece descrita por meio do uso do solo, das culturas de milho, de feijão, de fumo, de batata, de trigo e de outros cerais, justificando também o seu uso junto à criação de gado em pequena escala. Designadas como "terras em condomínio", essas áreas eram tomadas como sendo partilhadas por mais de um proprietário, o que nos permite relacionar que o título de propriedade, nesses condomínios, se apresentava sob a chancela coletiva e não individual (MACIEL, 2016). Nesse sentido, podemos entender que a terra, na perspectiva dos caboclos, era interpretada pelo sentido de partilha, domínio social por excelência, em que as justificativas para a sua existência não se estendiam para um outro mundo, messiânico, mas sim se vinculavam às práticas materializadas e envolvidas diretamente ali com o valor de apego e fixação dos sujeitos à terra. Ela ditava um 
valor ao mesmo tempo elementar e tradicional, acobertando, cobrindo e protegendo os diferentes sujeitos colocados em vulnerabilidade nas primeiras décadas republicanas e, especialmente, sob o avanço truculento do progresso em Santa Catarina.

\section{CONSIDERAÇÕES FINAIS}

Neste artigo, tentamos extrair de processos relacionais de subjetivação materializados na Guerra do Contestado singularidades a partir do conceito de terra. Esta interpretação sobre a terra coloca em perspectiva histórica, na qual os sentidos de entendimento do que venha a ser terra passam pelos valores que cada sujeito atribui à unidade do seu discurso. Propomos como desafio na abordagem sobre o tema junto aos movimentos sociais da primeira República, entre eles, além do conflito do Contestado, a Guerra de Canudos, pensar a terra enquanto conceito histórico definidor dos valores que estavam em conflito e eram colocados sob disputa pelos diversos grupos sociais nesse momento. Apresentamos a natureza e, por conseguinte, a terra a partir das perspectivas de alteridade na história do conflito.

A terra, conforme analisado na historiografia e nos documentos selecionados, era muito mais que uma peça material para a extração de produtos, pretexto de luta para a eclosão do conflito, suporte para a exploração de madeiras e colonização do interior: ela representa, como argumentamos, os conflitos de toda sorte que se divergem em relação ao que se entende e aos valores a partir dos quais se parte para interpretar a terra. Muito dessa projeção, como se suspeita, tem pouco a ver com as propriedades materiais da terra, mas sim com o que ela representa no interior do discurso dos diferentes sujeitos históricos implicados com a Guerra do Contestado. A polissemia que o conceito de terra recebe nos discursos de alguns sujeitos históricos envolvidos naquela Guerra deixa ver que sobre o conceito material de terra, bem como sobre a sua naturalização, há que se investir com uma leitura que desperte a historicidade dos seus sentidos.

\section{MARCELO HENRIQUE NOGUEIRA DIANA}

Doutor em Ciência Política pelo Instituto de Estudos Sociais e Políticos da Universidade Estadual do Rio de Janeiro (IESP-UERJ). Professor da área de História do Instituto Federal Catarinense (IFC), campus Araquari. Pós-doutorado no 
Departamento de História da Universidade Federal Rural do Rio de Janeiro (UFRRJ). Membro da Associação Nacional de História (ANPUH) e da Sociedade Brasileira de História da Ciência (SBHC).

\section{MARO LARA MARTINS}

Doutor em Sociologia pelo Instituto de Estudos Sociais e Políticos da Universidade Estadual do Rio de Janeiro (IESP-UERJ). Professor do Departamento de Ciências Sociais da Universidade Federal do Espírito Santo (UFES). Membro da Sociedade Brasileira de Sociologia (SBS), da Associação Latino-americana de Sociologia (ALAS), da Associação Nacional de História (ANPUH) e da Sociedade Brasileira de Teoria e História da Historiografia (SBTHH).

\section{REFERÊNCIAS}

A REPÚBLICA. Comentários. Florianópolis, 17 de julho de 1919, p. 3.

ARAUJO, Cicero. Tensões da Utopia Agrária. O rústico, o civilizado e o cidadão. In: STARLING, Heloisa; RODRIGUES, Henrique Estrada; TELLES, Marcela. (orgs.) Utopias Agrárias. Belo Horizonte: Editora UFMG, 2008, p. 128-149.

ASDAL, Kristin. The nature of "nature". History and Theory, Theme Issue 4, December 2003, p. 60-74.

BACH, Maurizio. Carisma e racionalismo na sociologia de Max Weber. Tradução de Markus A. Hediger. Sociologia \& Antropologia. v. 1, n. 1, 2011, p. 51-70.

AURAS, Marli. Guerra do Contestado: a organização da irmandade cabocla. Florianópolis: Editora da UFSC, Cortez, 1984.

BISHOP, Shermann. Relatório da Southern Brazil Lumber and Colonization Company. Arquivo

BISHOP, Shermann. Relatório da Southern Brazil Lumber and Colonization Company. Arquivo Público do Estado de Santa Catarina. 1917 (Maio). p. 1-21.

BOCCHETTI, André. Entre golpes e dispositivos: Foucault, Certeau e a constituição dos sujeitos. História da Historiografia, Ouro Preto, v.1. n. 18, p. 43-56, ago. 2015.

BRANDT, Marlon. "Mattas soberbas", "pastagens riquíssimas": a paisagem do planalto catarinense através do olhar dos militares da Guerra do Contestado (19121916). In: XXV SIMPÓSIO NACIONAL DE HISTÓRIA, ANPUH, 25, 2009. Fortaleza. Anais... Fortaleza, Universidade Federal do Ceará (UFCE), 2009, p. 1-10.

CARVALHO, José Murilo de. Coronelismo, mandonismo e clientelismo. In: CARVALHO, José Murilo. Pontos e Bordados: escritos de história e política. Belo Horizonte: Editora UFMG, 1998. p. 130-153.

CARVALHO, Miguel Mundstock Xavier. Uma grande empresa em meio à floresta: a história da devastação da floresta com Araucária e a Southern Brazil Lumber and 
Colonization (1870-1970). 2010. Tese (doutorado) - Departamento de História. Universidade Federal de Santa Catarina, Florianópolis.

CUNHA, Euclides. Os sertões: Campanha de Canudos. Edição crítica de Leopoldo Bernucci. São Paulo: Ateliê Editorial, 2001.

ESPIG, Márcia Janete. Breve estudo sobre o Movimento do Contestado: a historiografia militar e o caso dos operários da EFSPRG. Anos 90, Porto Alegre, v. 14, n. 25, p. 199-219, jul. 2007.

FOUCAULT, Michel. A arqueologia do saber. 7. ed. Rio de Janeiro: Forense Universitária, 2007.

IMPARCIAL, Canoinhas. 13/08/1916. Biblioteca Pública do Estado de Santa Catarina, Florianópolis, n. 34.

KOSELLECK, Reinhart. Futuro passado: contribuição à semântica dos tempos históricos. Rio de Janeiro: Contraponto, 2006.

LAZARIN, Katiuscia Maria. Lendo o Contestado: discurso e construção de sujeitos na bibliografia sobre a Guerra do Contestado - 1915 a 1960. Esboços, Florianópolis, v. 11, n. 12, p. 151-164, 2004.

LAZARIN, Katiuscia Maria. Fanáticos, rebeldes e caboclos: discursos e invenções sobre diferentes sujeitos na historiografia do Contestado (1916-2003). 2005. Dissertação (mestrado) - Departamento de História. Universidade Federal de santa Catarina, Florianópolis.

LEAL, Vitor Nunes. Coronelismo, enxada e voto. Rio der Janeiro: Forense, 1975.

LIMA, Nísia Trindade. Um sertão chamado Brasil: intelectuais e representação geográfica da identidade nacional. Rio de Janeiro: IUPERJ/UCAM, 1999.

LINO, Jaisson. A cultura material da Guerra do Contestado como documento histórico. Cadernos CEOM, Chapecó, v. 25, n. 36, p. 45-70, 2012.

MACIEL, Janaína Nevez. A questão da terra na região do Contestado: a regularização fundiária de Lages. In: XV ENCONTRO REGIONAL HISTÓRIA DA ANPUH/PR, 100 ANOS DA GUERRA DO CONTESTADO, 15, 2016, Curitiba. Anais... Curitiba, Universidade Federal do Paraná (UFPR), 2016, p. 01-14.

MACHADO, Paulo Pinheiro. Um estudo sobre as origens e a formação política das lideranças sertanejas do Contestado - 1912-1916. 2001. Tese (doutorado) - Instituto de Filosofia e Ciências Humanas. Universidade Estadual de Campinas, Campinas.

MACHADO, Paulo Pinheiro. Guerra, cerco, fome e epidemias: memórias e experiências dos sertanejos do Contestado. Topoi, Rio de Janeiro, v. 12, n. 22, p. 178-186, jan./jun. 2011. 
PAIM, Elison Antonio. Aspectos da constituição histórica da região oeste de Santa Catarina. Saeculum: revista de História, João Pessoa, n. 14, p. 121-138, jan./jun. 2006. 